John Bova*

\title{
Minimal Sartre: Diagonalization and Pure Reflection
}

https://doi.org/10.1515/opphil-2018-0026

Received October 12, 2018; accepted October 18, 2018

\begin{abstract}
These remarks take up the reflexive problematics of Being and Nothingness and related texts from a metalogical perspective. A mutually illuminating translation is posited between, on the one hand, Sartre's theory of pure reflection, the linchpin of the works of Sartre's early period and the site of their greatest difficulties, and, on the other hand, the quasi-formalism of diagonalization, the engine of the classical theorems of Cantor, Gödel, Tarski, Turing, etc. Surprisingly, the dialectic of mathematical logic from its inception through the discovery of the diagonal theorems can be recognized as a particularly clear instance of the drama of reflection according to Sartre, especially in the positing and overcoming of its proper valueideal, viz. the synthesis of consistency and completeness. Conversely, this translation solves a number of systematic problems about pure reflection's relations to accessory reflection, phenomenological reflection, pre-reflective self-consciousness, conversion, and value. Negative foundations, the metaphysical position emerging from this translation between existential philosophy and metalogic, concurs by different paths with Badiou's Being and Event in rejecting both ontotheological foundationalisms and constructivist antifoundationalisms.
\end{abstract}

Keywords: Badiou, Mathematical Existentialism, Metalogic, Negative Foundations, Reflexivity, SelfReference, Tetradic Dialectic, Value

\section{Multiplicity}

Minimal Sartre is early-period Sartre with interventions to maximize the ratio of direct formal-existential duality to phenomenological mediation, so that the crucial structures and arguments of Being and Nothingness and related texts can be reactivated in their complexity, significance, and normative charge, as systematic and unsystematizable philosophy. Absent from it are such staples of popular Sartre as "the look"; the elusive Pierre, holes and slime; and attributions of bad faith to food-service workers/victims of torture/others. It relies on an austere cut of Being and Nothingness, centered on Part II, "Being-for-Itself," along with the brilliant and relatively self-contained discussions which Sartre more-or-less-anxiously, moreor-less-playfully, brackets as "metaphysical" rather than "ontological" or "phenomenological": significant portions of the Introduction and Conclusion, brief treatises like that on totality adjoined to the final pages of "The Existence of Others"; and on relevant remarks from the Cahiers, particularly the "Plan for an Ontological Ethics" of the Second Notebook. As a point of discipline, it takes nothing at all from the most often cited, anthologized, and taught (but least philosophically successful) Sartrean texts-the motivating examples of Part I of Being and Nothingness and the popularization "Existentialism is a Humanism".

Minimal Sartre is also a Sartre after Badiou. The present remarks are addressed in the first instance to those readers who continue to find in Sartre's texts a source of insight and provocation, despite or even because of the fact that our axioms for a plausible ontology have been decisively de-phenomenologized by the lessons of that principal successor to Sartre's inquiry into the logic of reflexivity in the face of irreflexive

\footnotetext{
*Corresponding author: John Bova, University of New Mexico and New Centre for Research \& Practice, United States of America; E-mail: sunyataivarupam@gmail.com
} 
being, Alain Badiou's Being and Event. Accordingly, I begin by gladly acknowledging the many points of overlap between the post-Badiousian Sartre invoked here and the one introduced by Lucca Fraser in "Nothingness and Event," far and away the most logically significant text on Sartre in English by a member of the "Being and Event generation."

The most significant of these baseline ontological shifts lies in the necessary completion of Sartre's realism and externalism regarding intentional objects by Badiou's realism and externalism regarding multiplicity in-itself and (strictly on that basis) difference, order, and relation. Familiarly, the points of Being and Nothingness at which investigation stalls and begins to spin in self-presupposition are those at which Sartre runs up against his self-imposed axiom that the for-itself must be taken as the origin, rather than the product, of whatever goes beyond identity in non-conscious being: multiplicity, plurality, functions, relations, possibilities, change, motion, and difference. His effort is to say that it is not the being of these, but only their worldly status as multiple etc. which is derivative: "The in-itself is not diversity; it is not multiplicity; and in order for it to receive multiplicity as the characteristic of its being-in-the-midst-ofthe-world, a being must arise which is simultaneously present to each in-itself isolated in its own identity. It is through human reality that multiplicity comes into the world; it is the quasi-multiplicity at the heart of being-for-itself which causes number to be revealed in the world."2 Such indications point toward a better concept of the multiple than they succeed in articulating. They still officially suppose that multiplicity need not be made use of in the ontological story about its origin, i.e., that the ancient problem of the relation of the one and the many does not reach into being-in-itself. ${ }^{3}$ But the slippage in a single proposition between an extra-mundane multiplicity presupposed (or used: "each in-itself") and an intra-mundane multiplicity which can become an intentional object (or mentioned: "revealed in the world"), as well as the correlative slide between the for-itself as cause of being and of being-revealed for the multiple are typical ambiguities of phenomenological method, which attempts to carve out a sphere in which the interrelated differences being/appearing, use/mention, and meaning/reference can be appealed to or put out of play depending on the needs of the moment. If such a position is self-undermining, as I think it is, then the ontological status of multiplicity can, at least, never be disambiguated in Being and Nothingness with its commitments to both phenomenology and realism. ${ }^{4}$

It is impossible to treat here all of the advantages which philosophical experience, over the course of a long conversion, finds to accrue to a realism of the multiple. The simplest and most effective methodological argument for such realism will probably be a Russell-style one that extends the famous underivability of relations to multiplicity itself: if the for-itself is not able to presuppose real multiplicity in its very temporalization and spatialization, it will be unable to introduce it later by means of negation.

1 Readers of both papers will find that the divergences between their reconstructions of Sartre are mostly to be explained as the result of focusing investigation on the reflective $v s$. the pre-reflective forms of self-reference in the for-itself; of course a more complete reconsideration of early Sartre on post-Badiousian foundations will require integrating both of these approaches, as one cannot give a satisfactory account or assessment of either reflection or the pre-reflective in isolation. Even if, as I suspect, the clarification of reflection attempted here makes eliminativism about pre-reflective self-consciousness more palatable, the justificatory path, limits, and consequences of such an elimination must be carefully delineated, and I shall not attempt this here. Both skeptical evaluations of pre-reflective self-consciousness and vigorous defenses of its cogency on different grounds than those discussed here can be found in the contributions to Miguens et al., Pre-Reflective Consciousness: Sartre and Contemporary Philosophy of Mind.

2 Sartre, Being and Nothingness (henceforth BN), 196 / L'être et le néant (henceforth EN), 172. Note that paginations of the Barnes translation vary by edition.

3 “...This principle does not concern the internal relations of being; these relations, inasmuch as they would posit an otherness, do not exist. The principle of identity is the negation of every species of relation at the heart of being-in-itself." Sartre, $B N 124 /$ EN 113.

4 Nor can it be clarified, I suggest, from within phenomenology more generally, since the relative priority of these differences to consciousness (i.e., to the difference in-itself/for-itself) is precisely what is in question. We pass beyond the standpoint of consciousness when the persistence of multiplicity across the boundary of the reduction causes us to pass from the hypothesis, "There is a use-mention ambiguity because of the for-itself," to simply, "There is a use-mention ambiguity," and perhaps even to, "There is the for-itself because there is a use-mention ambiguity." Similarly, we pass beyond phenomenology when we think of the being/appearing and meaning/reference differences as always continuing to divide any supposedly-closed spheres of appearance or meaning per se, no matter how carefully reduced. 
Though thought tries to outrun this contingency as much as possible, the intentional relation to multiplicity involves participation in multiplicity from the beginning, at the level of its syntax, and all the more as it ascends in complexity. The for-itself may mark the center of orientation and indexicality, but it cannot be the origin of the multiple, or, as Sartre insists, the being of relation.

Now, these are precisely the points at which Being and Event takes its forward strides, while offering, as Fraser has shown, a recognizable sublation (read: upgrade) of the immobile, self-identical Sartrean in-itself in its commitment to a purely extensional treatment of multiplicities. Fuller consideration of these points would involve an analysis of the failures of the phenomenological derivations of spatial and temporal multiplicity in Being and Nothingness and the relation of these to the "metaphysical" framing remarks, as well as investigation of the-necessarily massively complex-structure of the for-itself itself ${ }^{5}$, in dialogue with functionalist and materialist philosophy of mind. ${ }^{6}$ For the space of this article, then, what recurs as Sartre's Eleaticism, whether intentional or an inadvertent function of the limits of phenomenological language, will simply be set aside an obstacle to philosophical work. The bottleneck choking the development of an adequate theory of relations in Being and Nothingness will be broken open; we shall presume that multiplicity is an original unmediated characteristic of being-in-itself and that there are on its basis more functions and relations in Being-infinitely more, as Cantor's theorem will show us-than those coming to it through the for-itself's intentionality. Such realism allows (indeed demands) an investigation of both the in-itself and the for-itself which cannot keep between itself and mathematics the distance that phenomenology always maintains from what it takes to be a founded and derivative formalism, but which instead recognizes mathematics and the reflection on mathematics as inseparable from ontology. Gone too is any sense that phenomenology has the conceptual power to cogently maintain that boundary between ontology and metaphysics that Sartre is always transgressing in bad conscience in Being and Nothingness. There is a natural rapport, accordingly, between suspicion of Sartre's phenomenology and renewed interest in his incipient metaphysics.

One may gather from the foregoing that the ontological material excised in our minimal Sartre is too extensive for anything significantly Sartrean to remain, and that retaining Sartre as a touchstone for philosophy in the present could only be a matter of sentimental regard for a tortuous path traveled toward a more satisfactory view. I hope to show here that this is not the case by exhibiting the phenomenon of the convergence of Sartre's problematic of reflection, including the themes of lack and conversion, with the structure of reflexivity disclosed in metalogical/metamathematical ${ }^{7}$ reflection by the quasi-formalism of diagonalization (described in section 3). I proffer this as a manifestation of a general convergence phenomenon: the structures and problems which emerge from metalogical reflection converge with the characteristic themes of contemporary philosophy. This convergence can be explained if (1) the problems

\footnotetext{
5 For the same must be asserted of the being of the for-itself: we will have to be able to thematize the complexity of a material system able to instantiate consciousness, which is a different thing both from the "quasi-multiplicity" which the for-itself is allowed to be, and the "body" that it is said to have-to-be. In that case, an adequate account of the relation between the for-itself and its being will take on this additional question: how does the most complex and differentiated thing known to us come to count itself as nothing, in order that "there is," for it, Being? That question, well-posed, goes some way toward suggesting its answer.

6 Excellent work has begun on especially the latter topic, on which Sartre's logic always wavers. See especially the essays collected in Miguens et al., Pre-Reflective Consciousness: Sartre and Contemporary Philosophy of Mind. For a closer discussion of the former than mine, see Fraser's This Infinite, Unanimous Dissonance, which defends Sartre's in-itself against the charge of Eleaticism by rethinking the in-itself in terms of the axioms of extensionality and foundation. I am happy to leave open the question of whether this is best described as a break with Sartre (as I am inclined to do) or simply as an unintended model of the in-itself. Such radical reinterpretations are, of course, exactly in the spirit of the one I am making here; I simply find it more natural to intervene at a different point, resigning myself to speaking a different language than Sartre's about the in-itself and the pre-reflective, and rejoining Sartre at the level of lack, reflection, and conversion, where the results to be preserved strike me as richer.

7 The double classification of the diagonal theorems as metalogical and metamathematical is as essential as the double classification of logic as a branch of both mathematics and philosophy, but pursuing this would take us too far afield; for present purposes, these can simply be taken as two different names for the same family of diagonal theorems. For ease of reading, I will often refer simply to "metalogic".
} 
of philosophy are characteristically the problems of self-reference, ${ }^{8}(2)$ this identity becomes generally increasingly self-conscious in contemporary philosophy, and (3) the true form of self-reference is exhibited by diagonalization (rather than, say, by paradox or by the vanishing of reflexive questions). ${ }^{9}$ The internal tension among these conditions makes them work; the risk, particularly, in (2) that self-consciousness about self-reference recapitulates a Hegelian Absolute, is more perfectly dispelled by the detotalizing consequences of (3) than by any external critique of dialectic. The truths of self-reference disclosed by diagonalization, that is, turn out to be more Sartrean than Hegelian, saying something strictly rational but strictly negative about totalization. It had been assumed, tacitly, for most of philosophical history, that mathematics, elevated and abased in philosophical discourse over endless cycles, would never speak about itself, but that if it did, it would surely weigh in on the side of its own perfection. Instead, when it began abruptly to speak about itself in the diagonal theorems, it not only announced the imperfection of its own discourse on form but, in doing so, articulated the form of the negation of the perfect in general. Diagonalization not only witnesses the imperfection of the theory of form, but inaugurates the theory of the form of imperfection (and perhaps, as I suggest elsewhere, the form of a Good better than the Perfect). Following out this chiastics, the instance of convergence explored here will, if successful, also lend support to the thesis that we can recognize metalogic as, effectively, a first-order study of those weird parts of reality in which philosophy takes especial interest-those, say, outside the zone of truth as systematic correspondence of propositions with properties of medium-sized objects-just as much as it is the secondorder study of the limits of formalisms that work at that level.

\section{Aporias of reflection}

It is well-known that two reflections are distinguished in the works of Sartre's early period: impure or accessory reflection and pure or purifying reflection. ${ }^{10}$ Pure or purifying reflection is the methodological and ethical heart of the texts, yet it is typically able to be indicated there only in marginal gestures-a footnote, an interruption, a framing remark, a digression discounted as metaphysical, a promissory note, a silence, and most characteristically, I think, an acceleration of logical and performative tempo, and a cross-contamination between levels of discourse. The most influential accounts in the small secondary literature on pure reflection have tended to assimilate it either to Husserlian phenomenological reflection or to Heideggerian authenticity. ${ }^{11}$ Of course, both points are partially correct. The very term is Husserl's,

8 Cf. Priest, "The Nature of Philosophy and its Place in the University", and Beyond the Limits of Thought, 4 et passim.

9 To point out the convergence thesis and to explain it along such lines was the project of my first round of dissertation research in the 2000s. A number of the texts and schemata with which I was concerned in this research have since been discussed in Paul M. Livingston's The Politics of Logic (2012), which can be consulted for a different development of many of the themes appearing in this paper.

10 I am textually unconvinced by Cannon's proposal to distinguish three reflections in the early period: impure, pure, and purifying. Pure reflection is neither static nor durative in Sartre; it has a plot and a trajectory (homologous, I propose, to the path of proof by contradiction in diagonalization). But I agree with what I infer to be the motivation behind the subdivision: if one thought that pure reflection remained phenomenological reflection throughout, then drawing a further distinction between pure and purifying forms would be a reasonable way of making space for the aspects of non-accessory reflection in Sartre‘s texts that exceed or otherwise fail to map onto phenomenological reflection. But it is better to make the more radical correction: pure reflection is dynamic, and to characterize it as purely subtractive with respect to knowledge is to mistake a logical process for one of its moments.

11 Already in The Transcendence of the Ego, pure reflection is "not necessarily phenomenological reflection," but readers reasonably conclude that this is only because phenomenological (read: Husserl's) reflection, is being criticized for having betrayed its own guiding idea of intentionality, and having deviated into a mode of reflection apparently disclosing but actually constitutive of the transcendental ego. On this reading, pure reflection, as it appears in The Transcendence of the Ego, is simply phenomenological reflection as it ought to be, minus this deviation. There are points in the work which resist this reading, but this interpretation is so closely aligned with the thesis of that text that it can only be called incomplete, not incorrect. Sartre will change his ground decisively by the time we arrive at Being and Nothingness, where having found a way to acknowledge the lack-value-self problematic at the heart of reflection changes everything. Because of its natural closeness to the value problem, The Emotions foreshadows this methodological break more legibly than The Transcendence of the Ego. In Being and Nothingness, the two readings are brought together: identification with the Ego is not just a mistake but a motivated and to that 
who uses it as a synonym for phenomenological reflection. So does Sartre-at first-who also draws the connection to authenticity repeatedly himself. But there are more problems to pure reflection than an assimilation to Husserl or Heidegger resolves. More promising is to approach it as a synthesis of the two. We can then formulate the important requirement of a reflection as rigorous as Husserl would require, which, qua reflection, needs to make an existential difference comparable, in magnitude, if not in form, to that of the self-recovery of Dasein in authenticity. But even this skips too easily over the problems of formulation and expression which make pure reflection characteristically Sartrean. Consider the appearance of a purifying reflection in Sartre's opening word on Husserl's phenomenology, intended to present the new method as a triumphant liberation from Neo-Kantian epistemology, but in which, from the beginning, Sartre is already found making Husserl say things that the latter would never say, in ways he would never say them:

Do you recognize in this description your own circumstances and your own impressions? You certainly knew that the tree was not you, that you could not make it enter your dark stomach and that knowledge could not, without dishonesty, be compared to possession. All at once, consciousness is purified, it is clear as a strong wind. There is nothing in it but a movement of fleeing itself, a sliding beyond itself. If, impossible though it be, you could enter "into" a consciousness you would be seized by a whirlwind and thrown back outside, in the thick of the dust, near the tree, for consciousness has no "inside". It is just this being beyond itself, this absolute flight, this refusal to be a substance which makes it a consciousness... ${ }^{12}$

This inaugural text is a knot of constatives and performatives, weird in what it says and possibly weirder in how it says it. Who is addressed here? When, "all at once, consciousness is purified," is this recognition or transformation? Does it take place in the reflective narrative time of the essay or in the time narrated? And most importantly, on what level of discourse is the event of purification invoked here supposed to be located? The reader is not invited to evaluate a claim without simultaneously playing a role in the drama of recognition. An event of katharsis is not simply described but indicated in such a way that it requisitions the "you" to whom it is addressed, not in a subsequent act of communication, but in its meaning. However we come at it, normal distinctions of level in discourse are collapsed at this point. Usually such level-crossings are simply errors. How do they become, here, the material of what is presented as a recollected truth? For the received interpretations, the performative dimensions of this text are a literary accident, clothing a content which could have been conveyed by the prose of Ideas or Being and Time. Sartre himself officially rejects the idea that the plurivocity of literary language can or should contaminate philosophical prose, but this protest counts for less than the appearance of the anomalies enumerated above whenever the question of pure reflection arises. In Being and Nothingness, too, whenever it is a question of pure reflection, the necessity of discourse to measure its own level becomes explicit and immediately problematic. The rhetorical context and the dimension of performance stick to the account of pure reflection as, in Lacan's famous image, to the bottom of its shoe, preventing it from becoming a fully free ideality in Husserl's sense. It would be a mistake to regard this as a pattern of rhetorical supplementation to a defective concept. Rather, the ambiguities of level are an essential part of the content conveyed. Pure reflection is not pure reflection without its thinker being led, Hofstadter would say, in a strange loop in which reflective ascent somehow descends beneath the level at which it started. Following this structural clue we will find in diagonalization a quasi-formalism which behaves in the same way, requisitioning the subject and collapsing the distance at which a proposition is entertained, through its exceptional material use of the signifier. For a formal system does not produce its diagonal sentence as a theorem; only "you" do, the same weirdly material and universal "you," I suggest, as the one addressed in "Intentionality".

If it could be successfully undertaken, a pure reflection would be an acknowledgment and affirmation of the condition that accessory reflection merely lives and propagates, not without confounding its own obscure intention to flight-a flight in bad faith, since flight is an intention not to know what it must know in order to intend flight. This contradiction in its own initial structure, closer to itself than any mental

extent structurally necessary distortion which can be understood in terms of reflection as a second project of self-recovery by the for-itself which lacks itself and strives toward itself as value.

12 Sartre, "Intentionality: A Fundamental Idea of Husserl's Phenomenology". 
"contents" or "states", is intimate enough to consign the for-itself to permanent-and meaninglesssuffering, and at the same time essentially nonlocal, sterile of graspable consequences for the for-itself. Conditioned by the evanescence of the phantom dyad reflection-reflecting (reflété-reflétant), consciousness in the project of accessory reflection plays on (and is played by) the elsewhereness of its impasse in a manner comparable to the stability of omega-inconsistency in a reflexively impoverished formal language. I believe that I will write the Great American Novel, say, but I do not believe that I will write it today, or tomorrow, or the next day... I believe only that I will write it one day, and this one day both is and is not a day. ${ }^{13}$

If the for-itself does not initially turn to affirm its condition, this is perhaps because what to turn toward is a nontrivial problem. It seems that the situation of the for-itself has invalidated in advance all possible headings of conversion. The orthodox existentialist responses of the form, "Not toward any point but toward itself", "A choice of something equivalent to a choice of itself," belong to the structure of the problem. They are what Socrates, in Plato's remarkably convergent discussion of reflection in the Charmides, calls a "riddle": appeals to itself-ness must on one hand be essential to capture the reflexivity of the phenomenon, but, on the other, demand further content in order to become intelligible or actionable; they place constraints upon a solution to the problem of the object of a pure reflection (or, for Plato, a true self-knowledge), but they do not solve the puzzle, at once existentially pressing and formally rigorous, "What does a consciousness (or for that matter a concept) that turns toward itself ultimately turn toward?" This difficulty has a structure, and we can add to the formulation of scope just cited-reflection can see neither how to include nor to exclude its intentionality from its own scope-a topological formulation of orientation: it seems that the for-itself can turn only toward or away from itself, and that either heading is groundless. The paradox of value in the original position of the for-itself is that both acts, turning toward and turning away from itself, seem to result in two different modes of turning away from itself. The bad faith of flight and the good faith of sincerity are both in bad faith. The attempt to know consciousness in accessory reflection simultaneously brings consciousness too close, since its flux defers knowledge, and keeps it too far away, since we have, in non-positional consciousness-(of)-self, a completely intimate relation without perspective, which is not knowledge. Accessory reflection is too ambitious and not ambitious enough for the same reason: that it attempts to combine the intimacy of consciousness with the perspective of another, a second person. Sartre thinks that the project of pre-conversion love tends to be a staging of accessory reflection: I want the Other to confer a being on me, yet I also want to destroy the Other in order to recover my freedom; such paralyzed projects are collectively and aptly called "Hell".

The scope difficulty and the topological difficulty are almost certainly just two ways of spelling out the same reflective dilemma. We might be tempted to dismiss these formal aporias of reflection as confusions

13 While Nietzsche‘s suspicion of the will to truth is given more currency in contemporary philosophy, Sartre‘s formally rich problematization of reflection's position relative to truth perhaps represents a deeper challenge to philosophy's account of itself: the aspiration to self-knowledge, unless ontologically clarified, does not necessarily represent anything like the approach to itself that it advertises itself as, but is even primarily a flight from existence into the appropriative distance of the knowledge (subject-object) relation. Accessory reflection may logically presuppose the truth of pure reflection, and display it by way of its own flight and failure in a way recoverable by the (small- $p$ ) phenomenologist-this is the wager of Being and Nothingness in particular, that "eidetic of bad faith," that "ontology before conversion"-but it does not turn to affirm its condition, and this avoidance of conversion, if anything, makes the question of the position of the phenomenologist more puzzling rather than being resolved by it. That the phenomenologist could successfully transpose consciousness's relation to itself-unable either to be or to escape itself, unable (in my suggested metalogical reformulation) either to include or to exclude its intentionality from its own scope-into a different, more playable key, is no more readily grasped than that consciousness, making a pass of its impasse, should directly escape from bad faith. Being and Nothingness, in particular, is a temporary compromise, a book split between the consciousness of the phenomenologist and the revealed structure of bad faith, which demands that the relation of the two be clarified while deferring its clarification each time it arises. Either the phenomenological reflection is one project in bad faith among others, in which case the standpoint of neutral witnessing that subtends its claim to truth is subverted, or else a radical conversion is possible through this reflection which passes to the level of first-order consciousness. Normative considerations of this type, undermining the possibility of the neutral descriptive stance feigned in Being and Nothingness, necessarily link that book, by way of a clarification of the problem of pure reflection, with its promised ethical sequel (which only ever appeared as notes and fragments). 
of language, were it not that they arise in the most regimented language with equal inevitability. The claim that we can be acquainted, in consciousness, with something that is always falsified by becoming a theme is not intrinsically more mysterious than the claim that we can understand the meaning of "of" even though the meaning of "of" is definitely transformed, even distorted, when it is made into the subject of a proposition, as in, " $O f$ is a preposition." Understanding such sentences plausibly requires first accepting and then finding a way to undo or compensate for the distortion of their subject that had to be tolerated in order to call attention to it. Thus with consciousness as well. This observation departs from what Being and Nothingness says, but only to underline what it does-the way that its methodology fundamentally relies upon a textual performance denied at the level of the ideology of an exclusively one-way relation of foundation between consciousness and the signifier. While most phenomenologists call for going back before the advent of these problems of nested quotation, or iterated reflection, Sartre, as I read him, does something different-he accepts the provisional statement of the problems of reflection with their internal paradoxes and tries to develop reflection forward to a point where the nonlocal paradoxes of the for-itself's inauthentic being can become momentarily locally fixed. This moment of pure reflection involves both a failure of reflection as knowledge, including phenomenological knowledge, and the collapse of the reflective hierarchy and the distance it presupposes, but also, inseparably, the success of reflection in establishing a new type of relation between levels of consciousness, and between meaning and existence, precisely in the virtual collapse of iterated reflection onto the plane of syntax, which is, for a moment, a plane of immanence, that is, a flat hierarchy as such.

The foregoing is intended to motivate treating Sartre's pure reflection as an open but coherent problem, on which we have reason to take the difficulties seriously enough to entertain radical interpretations, but have also some promising leads and constraints. Let us consider two such leads as constraints on a reasonable theory of pure reflection. Both come from the highest level of Sartre's early work, by his own estimation, that level which relates the for-itself to the being of value as lack of self. Each bears on the difficulties mentioned above: the first clarifies the proper object of a pure reflection, the second its structure.

1) There is, in Being and Nothingness, one definitive reference to a knowledge which comes by pure reflection. The text is architectonically crucial to understanding every section of "Immediate Structures of the For-Itself," and the official account of reflection as set out in the "Temporality" chapter, but it only comes to light, as if as a necessary afterthought, in the third section of the "Transcendence" chapter. “[L]ack,” Sartre writes,

can not be grasped thetically and known [connu] by the unreflective consciousness (nor does it appear to the impure, accessory reflection which apprehends it as a psychic object-i.e., as a drive or as a feeling). It is accessible [accessible] only to the purifying reflection, with which we are not here concerned. On the level of consciousness of the world, this lack can appear only in projection, as a transcendent and ideal characteristic. ${ }^{14}$

We confirm first that the disclaimer shows up precisely on schedule to accompany any reference to pure reflection. Second, we note the psychically-psychologically reifying effect of accessory reflection, familiar from many discussions in Being and Nothingness, The Transcendence of the Ego, and The Emotions. The crucial new information is that the alternative to such reifying projection is an intuitive but explicit grasp of lack. Pure reflection itself, of course, remains only a "quasi-knowledge" (quasi-connaissance) ${ }^{15}$ but the site at which it most directly connects to knowledge, according to Sartre, can now be precisely determined, and the nature of the interface queried. This is especially useful to note in resistance to readings which over-rely on the description of pure reflection as "simple presence" to the reflected-on. Such simple presence is, of course, also a necessary structure of reflection, but without pure reflection's intuition of lack, its meaning is completely up for grabs; this local simplicity of reflection per se may, as a matter of fact, not reify, but its meaning and norm is not yet the traversal through the point of contradiction in the value of totalization which initially and for the most part captures reflection, and which simple presence per se is powerless to 
speak of or against-value, or the global curvature of locally flat presence simply not being thematizable at the pre-reflective level. Simple presence is the ball in the air, but the players are competing structures of value. Further, the text provides a partial answer to the scope/object difficulty. Lack, or incompleteness on the ground of a projected completeness, is the proper object of a pure reflection distinct from anything that looks reducible to "simple presence" with the reflected-upon. Knowledge of incompleteness qua incompleteness, the kind which does not fall under the regulative ideal of a consistent completeness, but which instead refutes it, and demands that it should be dethroned as the form of value, comes by pure reflection. But knowledge of incompleteness also comes by diagonalization-this should, at least, make us wonder whether these two notions are internally related. Further, it follows in Sartre's tangled hierarchy that a reflection can be intuitive with respect to its proper object, as diagonalization will confirm in a way that, contra Penrose, does not inflate our epistemic powers-since the "faculty" it presupposes is simply our "faculty" for making mistakes, specifically type-errors. On the basis of this connection between pure reflection and knowledge of lack, the questions answerable only on a pure reflective level become more than promissory notes in Sartre's discourse. We can see him working them out in the text of Being and Nothingness, despite and through the demurrals, in the drama of lack, and certainly in the Notebooks. We can take from them directions and constraints on a theory, which, if uncompletable within phenomenology and in need of a radical supplement, still responds to a real problem.

2) If the first clue is proximately about the object of a pure reflection, the second is about its structure, specifically about its adicity, once again in the presence of the problematic of value, which has a triadic structure: lack of- by- for-, where the for-, or the lacked per se, is the synthesis of the existing and the lacking. Accessory reflection is thus triadic. But pure reflection is tetradic. We must search for it among forms which, while aiming at synthesis as a third and final term, explicitly produce, as the truth of reflection, a repetition of duality:

\begin{abstract}
The appearance of pure reflection constitutes another type of existence in which the project as pure existence, whose dimension is nonthetic consciousness (of) self, is at the same time thematized and called into question within the detotalized reflected/reflecting unity... The modifications brought about by nonaccessory reflection (which is not a form of contemplation but is itself a project) are the following: A new, "authentic," way of being oneself and for oneself, which transcends the dialectic of sincerity and bad faith. This way of being has four terms this time: reflected (reflection/reflecting), reflective (reflection/reflecting). [Cette manière d'être est à quatre termes cette fois: réfléchi (reflet-reflétant), réflexif (reflet-reflétant). $]^{16}$
\end{abstract}

Sartre's pronouncement in the Cahiers has drawn attention for its affirmation of a new existential possibility, but the status of this text as one of the central propositions of Sartre's theory of pure reflection rests not on the "new authentic way of being oneself," which indeed announces the high existential-ethical stakes of the transition to pure reflection, but on the clarification of a formal shift in the adicity of reflection necessary to its accomplishment. "This time," contrasts with accessory reflection, which was normatively triadic. Pure reflection does not confine itself within the instant, but Sartre is puzzled in Being and Nothingness, how to escape it without reinscribing the norm of totalization. He is right to be puzzled; the solution is nontrivial. Remarkably, he leaves the place of the central concept of his first system open in response to this puzzle, inviting solutions. But here, Sartre clarifies that the possibility of pure reflection rests on the supplanting of the triadic dialectic of lack by a tetradic dialectic that redoubles and repeats the "phantom dyad" of the for-itself. What formal effects does this revision have, and, given that the cited lines comprise the entire definitive discussion of the change in adicity between accessory and pure reflection found anywhere (to my knowledge) in Sartre's corpus ${ }^{17}$ what formal background can be brought to assist their intelligibility?

The problematic of pure reflection has demanded, at a phenomenological and ethical level, the establishment of a new norm that is no longer triadic, i.e., in which reflection, initially a form of

16 Sartre, Notebooks for an Ethics 474-5, emphasis added, corrected. The Chicago translation introduces a fifth term which is not present in the French text.

17 That reflection simpliciter takes this form is presented in the Temporality chapter of Being and Nothingness only as an obstacle blocking the aspiration of accessory reflection, and not as the repetition which itself delivers the truth of a pure reflection. 
representation in the service of an ideal of self-recovery or value, pushes through this ideal and opens on an unforeseen relation to itself and existence. We will see in the next section how diagonalization suggests that this dialectic is formally inscribable, on the condition that the formalization of dialectic pays for its hubris with a dialectic of formalization, and that it depends at a crucial point on the functions of the signifier. The natural framework for discussing this, of which I shall make use, is the Peircean triad, most familiarly icon/ index/symbol, which originates in dialogue with Hegel's dialectic, and in turn provides the formal basis of Lacan's theory. But the question which forces our attention is whether the appeal does not reinscribe, on the semiotic plane, the triadic logic which we were trying to refuse. It does not. But to establish this, the logic of a pure reflection demands that a critical question be raised, on behalf of the friends of the dyad and the tetrad (Sartre, Plato, and Badiou) toward the friends of the triad (Hegel, Peirce, and Lacan): Was there ever a semiotic-or dialectical-triad? Peirce's insistence that he (perhaps he alone) had mastered the form of counting proper to philosophy and mathematics, that it finally went, for all its internal complexity, one, two, three: was all of this perhaps grounded by the seductions of internal coherence and lack of an intuitive alternative? Specifically, we must ask whether there was ever a "symbol," i.e., whether a sign ever manages to signify by convention or association. Is the symbol a third proper form of signification on the level of the icon and the index (or even higher), or is it simply the name for an inert signifier as such, uncoupled from the circuits of signification, no functional part of the system of signs, but at best its practico-inert dimension? The stakes of the question include the very existence of "the symbolic" as such, regarding which Sartre seems almost premodern in his indifference, in the early period, to either "analytic" or "continental" versions of the linguistic turn, as well as the dogma of the arbitrary signifier. But what alternative is thinkable? Well, what if the tetrad precedes the triad? What if there were first these two terms, icon and index, and the two places, the Same and the Other? And what if-as has happened before-the place of the Other turned out to be non-negligible? Suppose accordingly that the illusion of a third kind materializes from the transparency of the Same and the opacity of the Other. On this hypothesis there would be no symbol per se, but the function of the symbol would be that of the Other: the icon-for-the-index, a constitutively excluded limit point, conflated with the index-for-the-icon (likewise). Something, indeed, closely linked both to diagonalization and to Platonic dialectic, happens if we actually throw these points of dysfunction together at the highest level of abstraction, if we say that the Other is, in a way, selfsame, and try to determine what that way is. But it seems instead possible to imagine this conflation, the selfsameness of the Other, as the linchpin of the "perfect system of logical notation" (Peirce) or Absolute knowing (Hegel), only if we keep from trying it out and observing that its function is dysfunction, its product the death of meaning. Does the motivated boldness of the imagination-its imaginary boldness-consist, upon raising the dangerous question of the meaning of "meaning", in refraining from actually taking the last step of an experimentum of semiotic breakdown in order to keep imagining transcendence as synthesis? What local evidence could persuade us to cultivate that global suspicion? This: if under analytic pressure the signifier on the one hand and "meaning" on the other keep splitting, not just into a coordinated pair consisting of icon and index, but into a pair consisting of one or the other paired with a badly infinite, dysfunctional remainder. In this story of doubling, to speak a little after the style of John Horton Conway, the one occurs "on day one", the two on day two, the four on day three, and the three only on day four, by limitation and conflation, when the Other is mistaken for a term of the System. This is not to say that such ambiguity, the attempted binding of the Other into a term, is never productive; indeed, it seems almost to institute and perpetuate-to produce-a myth of production and to cover over what in the system cannot, at the level of truth, even function, much less signify, or what is finally the same thing for the pragmatist, produce. System: "productive" ambiguity, ambiguity of production. But in this alternative genealogy of the triad, we can begin to see the basis for that same sudden suspicion of triadic logics which separates Plato from Aristotle, Sartre from Hegel, Badiou from Lacan, and all from the System; the common thread which holds together Plato and Sartre, and which thereby has made Badiou's work possible, is their recovery of dyadic (or tetradic, but never triadic) dialectic. The defense of this point demands its own investigation which cannot be carried out here, but we can take courage from the conceivability of an alternative and hypothesize here that, in exploring the relation of index and icon in reflection, we may not only not be failing to interrogate the third term of the semiotic triad, but accessing an infinite duality prior to the reification of a third type. 
On the basis of this hypothesis, let us end this section with a reformulation of this problem, leading to a final formal constraint on a theory of pure reflection. For Sartre, reflection is a new internal division of consciousness in which the for-itself makes itself the object of its own positional consciousness, simultaneously inducing entwined relations of proto-knowledge (since the reflecting seeks to know the reflected-on) and of being (since the reflecting is the reflected-on). There is no guarantee that these two aspects of reflection are consistently or helpfully coordinated in advance. In fact, Sartre maintains that they appear first as an incompatible duality, expressed in an indefinitely extendable set of problems which the for-itself solves poorly initially and for the most part, relative to both logical and axiological norms. The tie of being between reflection and the reflected-on seems both to enable and disable the project of selfknowledge; bringing the reflected-on close enough for knowledge to be possible, reflection finds it too close for knowledge to stabilize; the bond of being becomes the guarantor of the Cogito and its obstacle in the same stroke; the conditions of reflection's possibility are identical to the conditions of its impossibility. Reflection is accordingly for the most part inadequate. It systematically falsifies its own data and misrepresents its position in this second sailing toward selfhood, and this obscuration, simultaneously active and passive, extends the interval in which the value of selfhood can remain sovereign and unquestionable. At the same time, however, this problem presents to metalogical inquiry a further formalizable criterion for a pure reflection: if the bond of knowledge is encoded by the icon, a sign which signifies by resemblance to its signified, the bond of existence is inscribed by the index, a sign which signifies by being caught up in the same causal chains as its signified. In ordinary knowledge and experience, we need only to cope with this internal duality of meaning, constituting the lived and social worlds and the objects of knowledge proper to those milieux, perhaps, precisely by losing track of the difference after a finite number of reflective steps. (The inadequacy of our coping is our coping.) The problems of the second-order relation of these two dually signifying relations, however, recurs urgently for reflection, at the minimal and maximal limits of intentionality and signification-in the context of an intentionality, say, which wants to grasp itself exactly qua intentionality, or one which wants in some way to orient itself relative to the totality of being. The true relation of icon and index in intentionality, reflexivity, and totality must then be puzzled out, in order for the possibility of a true reflection to be intelligible, even while their duality keeps redividing the problem-icon and index have to be distinguished, on the side of knowledge, and yet caused to intersect, on the side of existence. Is there any hope of resolving this riddle without contradiction, self-presupposition, or regress? Is there a different original and total structure of the relation of icon and index than that of inconsistent coping haunted by the projection of their systematic synthesis, always out of reach? I suggest that diagonalization, introduced in the next section, provides precisely this purification, for there, the intersection of two reflectively-related iconic series induces a further intersection of icon and index. That such an intersection requires two iconic series, one of which is reflectively aimed at the other, is the key to the intelligible link between reflection's cognitive and existential moments.

\section{Diagonalization}

As the critical forms and arguments in early Sartre essentially involve and convoke self-reference, both implicitly in the pre-reflective structure of the for-itself, and explicitly in the drama of accessory reflection and its conversion by and to pure reflection, they must necessarily come into contact with the form of any sufficiently precise and general self-reference, given, I submit, by the quasi-formalism of diagonalization. My primary purpose in this section cannot, for reasons of space, be to present to a completely unfamiliar reader the formal structure of diagonalization without any presuppositions. ${ }^{18}$ Rather, it is to explore and integrate the philosophical significance of this quasi-formalism, by bringing it into intimate contact with texts of apparently very different provenance, allowing each reciprocally to interpret the other. ${ }^{19}$

18 Excellent introductions exist answering to this purpose, however, as do monographs developing the formal side of the inquiry, generally without philosophical considerations, far beyond what is needed here. Sometimes these are the same works. Some of those which have been particularly useful to me are included in References.

19 In this, I aim to contribute to a retroactively recognizable lineage of metalogical philosophy including the works of Hofstadter, 
Nevertheless, while some familiarity with intermediate mathematical logic is presumed, a brief appearance by "the diagonal itself" in this reflection on its meaning and use may be helpful to the reader, not as an introductory teaching, but, as Plato says, as a formal reminder for those who have encountered it, but require reactivation before philosophical use can be made of it.

The best way I know for the philosopher to be reminded of diagonalization is to begin not with definitions, which belong to one or another line of generalization, ${ }^{20}$ but by letting the idea of diagonalization speak for itself in the instance of it which comes first historically and logically, i.e., with Cantor's 1891 version of the proof of his theorem (the "much simpler" formulation involving diagonalization). ${ }^{21}$ Cantor is proximately concerned with "manifolds." The scope of this term expanded over the course of the nineteenth century, starting from Kant's strictly continuous manifolds inherited from the physical application of the NewtonianLeibnizian calculus, and progressively weakening the continuity requirement until it disappears entirely. Thus Cantor's "manifolds", unlike Kant's, have become pure multiplicities or "sets", not necessarily structured by continuity relations. Cantor's theorem shows us that this is a far more general notion; in fact, at each level of the complexity hierarchy, it is the discontinuous multiplicities which will make up the entire functional excess over lower levels, while there are, for instance, no more continuous functions of a real variable than there are real numbers. ${ }^{22}$ Speaking in terms of manifolds, we emphasize the univocity of this open universe. Manifolds are what all the inhabitants of Cantor's hierarchy are in-themselves. But they are also naturally understood in terms of functions which are of the manifolds of the previous level; this is what makes the theorem able both to globally establish and to locally suspend (but in both cases to be about) a hierarchy of concepts about each other, i.e., a reflective hierarchy, though the possibility of this interpretation was not seen clearly until Gödel made it the basis of the first incompleteness theorem. Thus the play of being and being-of, a nonstandard but useful first approximation of the duality in-itself/for-itself, is built in here, not only in its ground instance, but in its elaboration into the field of reflection. Cantor's theorem will both explain and relativize the difference, in absence of an absolute totality in relation to which the concept/object difference could be globally defined.

In the 1891 text, Cantor begins by proving the special case of the theorem, i.e., that the cardinality of the reals exceeds that of the naturals, using the familiar tabular form of the argument. In this, advantageously, the diagonal subset appears plainly as the literal diagonal of a two-dimensional lattice of signs, but at the price of claiming to present an infinite literal lattice, opening the argument to irrelevant finitist objections. More essentially for us, Cantor then reflects on the proof and extracts its principle in order to ascend to the general case:

Putnam, Badiou, Grim, Priest, Petersen, and Chaitin.

20 "Generalizations" of the diagonal theorems abound and are useful for various technical purposes. For metalogical philosophy, prioritizing reflexivity, however, caution is always indicated in their use. There is no such thing as a generalization simpliciter; every generalization adds cases and loosens restrictions along some chosen line of interest. If one fails 1) to identify this line, 2) to ask about its emplacement in the space of theory, and 3) to ask what that hybrid and exceptional quasi-formalism of diagonalization being generalized has to say about that space of theory, one blurs the distinction between the singular point of diagonalization and one or the other of the ordinary forms which diagonalization exceptionally hybridizes: paradox (which generalizes toward the ontotheological orientation) and technique (which generalizes toward the constructivist orientation). One thereby loses the thread of metalogical philosophy.

21 Badiou's readings of Cantor's theorem tend to be found toward the beginning of his systematic works, rightly, since, on my view, all of his subsequent philosophy depends on and unpacks these readings. They can be consulted at the session of February 6, 1978 in Theory of the Subject, the seventh and twenty-sixth meditations of Being and Event, section 2.1.1 of Logics of Worlds, and sections II.6-7 of the "General Introduction" to L'Immanence des vérités. And yet, Badiou interestingly avoids philosophically thematizing diagonalization as such, even in Being and Event, in favor of the related but distinct concepts of the generic and forcing. I would like to demonstrate, by example, some of such a thematization's utility here. If the reader wishes to follow the logic of diagonalization itself, as distinct from its output, in Being and Event, the term to track is not "diagonal" but "double function".

22 Discontinuity opens the quantitative-qualitative difference between the set of elements and the set of parts (or powerset) which I follow Badiou in identifying with ontological difference. This fact should be borne carefully in mind in assessing all contemporary philosophical use of sets that are in any way structured by a presumption equivalent to continuity (as is often the case with categories and topoi). 
This proof is remarkable not only because of its great simplicity, but more importantly because the principle followed therein can be extended immediately to the general theorem that the powers ${ }^{23}$ of well-defined manifolds have no maximum, or, what is the same thing, that for any given manifold $L$, we can produce a manifold $M$ whose power is greater than that of $L$.

Let, for instance, $L$ be a linear continuum, say the totality of all real numbers which are $\geq 0$ and $\leq 1$.

Let $M$ be the totality of all single-valued functions $f(x)$ which take only the values 0 or 1, while $x$ runs through all real values which are $\geq 0$ and $\leq 1 .{ }^{24}$ That $M$ does not have a smaller power than $L$ follows from the fact that subsets of $M$ can be given which have the same power as $L$ - for instance, the subset which consists of all functions of $x$ which have the value 1 for a single value $x_{0}$ of $x$, and for all other values of $x$ have the value 0.25

But $M$ does not have the same power as $L$ : for otherwise the manifold $M$ could be brought into a reciprocal one-to-one correspondence with the variable $z$, and $M$ could be thought of in the form of a single-valued function of the two variables $x$ and $z$ such that to every value of $z$ there corresponds an element $f(x)=\varphi(x, z)$ of $M$, and, conversely, to every element $f(x)$ of $M$ there corresponds a single determinate value of $z$ such that $f(x)=\varphi(x, z) \cdot{ }^{26}$ But this leads to a contradiction. For if one understands by $g(x)$ the single-valued function of $x$ which takes on only the values 0 and 1 and is different from $\varphi(x, x)$ for every value of $x$, then on the one hand $g(x)$ is an element of $M$, and on the other hand $g(x)$ cannot arise from any value $z=z_{0}$ of $\varphi(x, z)$, because $\varphi\left(z_{0}, z_{0}\right)$ is different from $g\left(z_{0}\right)$.

But if the power of $M$ is neither smaller than nor equal to that of $L$, it follows that it is greater than the power of $L .^{27}$

With $g(x)$, Cantor has essentially said, consider the diagonal of the lattice $L \times L$, where the first $L$ is understood as the set of elements of $L$ in their own right, and the second as the set of these as indices, by hypothesis, of all and only the elements of $M$. This lattice should be taken as the space of a systematic reflection; for the space of reflection to be complete would thus be equivalent to establishing a one-toone correspondence between the levels of set and powerset (presumably in an infinite case, since the failure is obvious for any finite case). The diagonal step, despite and because of the obtrusive role of the signifier in it-it produces a syntactic monster essentially without natural first-order interpretationis taken precisely for the sake of the systemic consequences of the change in adicity it effects. On the diagonal, some relevant properties of the proposed system of functions and arguments (or of concepts and objects), that hypothetical two-dimensional array, are captured, so to speak by accident, in a onedimensional array. But then this array, fatally, ought to belong to the set of one-dimensional functions already indexed by the system. So, too, should its modification by negation or any other fixed-point-free alteration. The remainder of the demonstration allows the diagonal in this rectilinear form to reintersect its literally diagonal form. At the point of intersection is localized the contradiction in the supposed system as a whole. Note that this thought, like Sartre's, is intrinsically both systematic and anti-systemic. Its correct interpretation is in terms of a posited synthetic system of concepts and objects, or, allowing nonstandard models of Sartrean terminology, of the in-itself and for-itself. But its valence is unremittingly negative; it says of this system that it (in Sartrean terms: the in-itself-for-itself), is a contradiction. The truth of reflection negates the apparently unsurpassable value which motivates reflection. Finally, this

23 Here, of course, the "power" of a set is its own cardinality, not that of its associated powerset.

24 That is, $M$ can be regarded as the set of all extensionally distinct maps (functions) from $L$ to $\{0,1\}$, i.e., as the object $2^{|L|}$. The notation is not equivocal; this map-collecting relation is precisely what the relation of base to exponent is, more fundamentally than it is repeated multiplication. (Like the relation of the inequality and inclusion relations on display in Cantor's next paragraph, the two coincide in the finite but are distinct in the transfinite.) It is easy to see that there are literally $2^{n}$ maps of $n$ objects to $2=\{0,1\}$. Cantor's theorem then gives a unified definition of this cardinal sense of $2^{n}$ for transfinite $n$ and shows that $2^{n}>n$, regardless of whether $n$ is finite or infinite. This is the discovery that makes set theory nontrivial, converting the infinite from the stopping point to the starting point for philosophical-mathematical reflection, but it is also one on which current axiomatizations of set theory seem to block further progress, that is, one whose further determination shows every sign of lying outside the power of the standard axiomatizations. As so often, the inaugural step of a theory encodes its limit. Of course, like Pythagoreanism itself, the intellectual project of set theory is rare precisely in its ability to encounter and acknowledge this limit and to demand innovations of thought beyond the given fixed formal systems. For further discussion see Badiou's treatment of the Continuum Hypothesis in Being and Event and the forthcoming Immanence of Truths.

25 Of course, Cantor means one $\mathrm{x}_{0} \in L$ per extensionally distinct function $f$, not one for all. $(\forall f \in M)\left(\exists x_{o} \in L\right) \ldots$ not $\left(\exists x_{o} \in L\right)$ $(\forall f \in M) \ldots$

26 Note that $z$ is a variable introduced to index the functions (from $L$ to 2) comprising $M$ by the elements of $L$. Its existence is another way of stating the hypothesis that $L$ suffices to index $M$, i.e., that they have the same number of elements.

27 Cantor, "On an Elementary Question in the Theory of Manifolds (1891).” 
truth is the proper object of such a purifying reflection, in its double aspect as a first-order intentional state, or observation about a proper object, and a second-order negatively reflexive state bearing witness to the failure of the system.

The nonstandardness of the model entails a clarification of the relation of in-itself and for-itself from the side of the in-itself, such as can account for the "absolute event" of the emergence of the for-itself, which Sartre tries to put off the table in Being and Nothingness as metaphysical rather than ontological. The distinction is unconvincing. The demonstration accomplished by that text, that the intentional relation between the foritself and the in-itself is nothing but the for-itself, demands as its dual an account of the causal emergence of the for-itself's intentionality from non-intentional processes. (Call it Nausea 2.0). This is the immediate relation for which the project of "naturalizing" phenomenology tries to reach too directly as a mediation, without having reached the disjunctive ground of metalogic, where such dual equivalences are not just explicable but inevitable. Thus the nonstandard step is simply to admit that everything descriptive which can be said of the for-itself's intentionality, as opposed to the normative dimensions of truth and completeness which it posits to the extent to which it reenters the zone of the intentional as properly for-itself, can be accounted for functionally. Since the alternative is a descriptive consciousness-mysterianism or qualiphilia on the border of which phenomenology endlessly hovers, the nonstandard move is an attractive feature.

In now-standard set-theoretic syntax, the general form of Cantor's theorem becomes the following: We suppose for reductio that there is some set $S$, be it finite or infinite, which can be put into isomorphism with its powerset $\wp(S)$, the set of all subsets of $S$. Call this isomorphism $f$. Observe that for any element $x$ of $S, x$ happens to fall either inside or outside its associated subset $f(x)$. So the existence of $f$ induces the existence of a subset $D$ (for "diagonal") of $S$, possibly empty, such that $d$ consists of all and only those elements of $S$ which fall outside their image under $f$, that is, $D=\{x \in S: x \notin f(x)\}$. By hypothesis, $D$ is paired by $f$ with an element $d$ of $S$, i.e., $(\exists d \in S)(f(d)=D)$. Ask: does $d$ fall inside or outside of its image, $D$ ? 1) Suppose $d \in D$. Then, by definition of $D, d \notin f(d)$. But $f(d)=D$, so $d \notin D$. Contradiction. 2) On the other hand, suppose $d \notin D$. Then $d \notin f(d)$. So $d$ satisfies $x \in S$ : $x \notin f(x)$ and by definition of $D, d \in D$. A symmetric contradiction. The only relevant assumption here is that of the existence of the isomorphism $f$ between $S$ and $\wp(S)$. Therefore $f$ does not exist. ${ }^{28} \mathrm{~A}$ second, equally useful reading is that any $f$ that does exist is not surjective, $a$ fortiori is not an isomorphism, because as defined above falls outside its range. In particular, the cardinality of the powerset, $\mid\left(\wp(S) \mid=2^{|S|}\right.$ is strictly greater than the cardinality of $S$, whether $S$ is finite or infinite. The infinite, after Cantor, is no longer that stopping-point at which a maximum of difference can be gathered into a maximum of self-identity, and no framing totality henceforth guarantees a rigid difference between functions and multiplicities (or between what counts as for-itself and as in-itself in a given context).

The liberation of diagonalization from a narrowly set-theoretical mooring has been performed numerous times. The first incompleteness theorem is arguably already an instance of this, and poses the perpetual problem of whether such resituations are limitations or expansions or (most likely) both in different senses. Particularly notable is Lawvere's reformulation of a large family of diagonal theorems in a categorical setting. Yanovsky performs a signal service by retranslating this back into a set-theoretic framework, thus attaining a measured degree of generalization in a context in which philosophers can still be sure that intensions and extensions are being given their intended interpretations. ${ }^{29}$ In the Lawvere/ Yanovsky reformulation, set-theoretic in its inferential structure, but presented in the categorical style by means of a commutative diagram, Cantor's diagonalization becomes (with my relabelings):

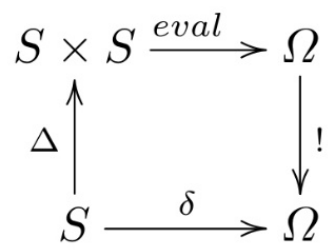

28 A second, equally useful, reading is that any $f$ that does exist is not surjective, a fortiori is not an isomorphism, because $D$ as defined above falls outside its range.

29 Yanofsky, Noson S. “A Universal Approach to Self-Referential Paradoxes, Incompleteness and Fixed Points.” 
With relabelings, this abstract presentation models equally well the uses of diagonalization by Gödel, Turing, Tarski, etc. (though so does Cantor's theorem itself, we come to see, in part through experiments of this sort). It is the central wager of my investigations here that the quasi-formalism now presented in three ways, which emerged unexpectedly from formal mathematics' reflection on itself (i.e., reflection on the matheme) is also the matheme of reflection, that is, that it exhibits, by participating in it, the essential trajectory of the self-application of the concept, whether this be called knowledge of knowledge, thinking of thinking, or even consciousness of consciousness, placing it in relation to a lack and excess that is at once reflection's limit and its ownmost possibility.

The diagram can be read as the disturbing fixation of the true mediating relation, by its ascending and descending arrows, between its two levels-the level of first-order cognition at the bottom and the level of reflection at the top. The emergence of the true mediation is disturbing because the content of reflection's articulated truth is ironically identical to the recognition of its weakness. The specification of reflection's true relation to the pre-reflective has, as the fruit of its exceptional evental success, the breaking of the image of an accessory (Sartre) or Critian (Plato) faculty or power of reflection. ${ }^{30}$ The diagram works by producing, as $\delta$ or the diagonal function, a first-order witness of the failure of the reflective functions at the top to successfully inventory or index the first-order functions at the bottom. Note that, in Sartrean terms, this indicates an excess in pre-reflective intentionality which cannot be captured by an accessory reflection; at the same time the truth of this excess cannot be witnessed by the pre-reflective itself, but only by a purified reflection. The priorities of the pre-reflective and the reflective are thus appropriately distributed. Here, $S$ is any set, of course including infinite ones; $\Omega$ is the truth-value object (classically 2 ); ! is any "derangement", that is, negation or any other fixed-pointless difference; eval $(x, y)$ returns the result of the function named by its first/second input applied to its second/first input; and $\Delta$ is the "diagonal functor" requiring us to consider the application of each function to its own index, for some putative indexing scheme. The term "diagonalization" is sometimes used narrowly to indicate only the application of this functor; I reserve it for the construction as a whole, and especially for the resultant function $\delta=!(\operatorname{eval}(\Delta(\mathrm{s})))$, which is the crux of the diagonal theorems as a class, the central topic of philosophical interest, and which would otherwise go unnamed. Diagonalization in my sense thus includes as elements both the production of a fixed point through the use of the diagonal functor, and the exclusion of a fixed point from at least some intralogical operation (that is, some function from the truth-value object to itself). This distribution of fixed points is the essence of the discovered mediation between the two levels of reflection which enables us to evaluate reflection's global structure. One way of putting the necessity which the diagonal theorems express is this: if you exclude a fixed point over here, in the definition of negation, say, then you must pay the price of rediscovering it over there, that is, finding that the fixed point of reflection is not a facultative Critian power of knowledge of knowledge, but an exceptional Socratic knowledge of ignorance. The concept stands in more relations than it can objectify, i.e., more than it can have a second-order concept of. This quantitative lack and excess would be, on my reading, the relevant instance of the Platonic Dyad lack/excess in contemporary thought, alike from Sartre to Badiou and from Frege to Davidson. In Sartrean terms, coming to a clear awareness of this means the overcoming of the form of pre-reflective value, namely the in-itselffor-itself as the fixed point of negation, in favor of the disclosure of the project as essential incompleteness or inexhaustibility. In Platonic terms, it means the appearance of a Form of the Good better than the Perfect Being of ontotheology.

Against the obvious metaphilosophical objection, it should be noted that the proposal put forward here to identify diagonalization with the truth of a sufficiently general reflection, whether this be called pure reflection with Sartre, the Idea of the Good with Plato, or by any other name, is not disqualified as a category error by its form, viz. an equation between a quasi-formalism on the one hand and a philosopheme standing in relation to (more-or-less) ordinary language on the other, for this feature is shared by the ChurchTuring thesis, of which it is in fact a proposed extension. The Church-Turing thesis, almost universally accepted, proposes an unprovable equation between a particular intramathematical formalism (actually

30 See Plato, Charmides, 169d ff. I elaborate on this connection in my 2016 dissertation, A Metalogical Approach to the Problems of Reflexivity in Platonic Dialectic, and in forthcoming work. 
three which prove to be equivalent) and the informal notion of an effective procedure, algorithm, or simply what it is to follow a rule. Working in the opening made by Badiou, I am attempting to contribute here to the construction of the dual and perhaps more difficult interpretive bridge which must be built between the uncomputable in life and its form.

\section{Minimal Sartre}

Clearly difficult problems, simultaneously existential and formal, are incurred by Sartre's gambit of going forward, allowing the problems of self-reference both in pre-reflective and reflective consciousnesses to be posed and pushed to the point of their greatest tension. This obviously leaves the door open to the disparagement of his phenomenology qua phenomenology, for failing to think back before reflection; but it is also what makes Sartre's investigations so rich a source of inspiration for a post-phenomenological reading which would recognize in them, despite his intentions, the presence, indeed the determinative presence, of a dialectical experiment of formalization. Reflection is necessary in order to call attention to being-for-itself, but produces distorting effects that have to be undone in understanding-fulfilling them. It thus has the topology of a cycle, the crucial points of which are not the self-objectifying and purely intentional extremes, but in each case the crossing of levels between the two, the entanglement between the logical levels of intentionality and self-reference that repeats, qua reflection, the level-crossing play of reflection-reflecting that constitutes consciousness to begin with. Only a hybridization of the schemas of the intentional vector and the reflexive loop could manage to fulfill the criteria of both intentionality and reflexivity, resulting in a reflection at once true and enacting a revealing participation in pre-reflective consciousness, where either form taken naively fails. But it is not clear to purely philosophical discourse that this third form exists, that there is any conceivable architecture of the reflexive concept that avoids the hierarchy of metalanguages on the one hand, and the ill-founded loop of nous on the other. Thus the importance of the identification of the form of diagonalization toward which Sartre's descriptions of pure reflection point. The quasi-formal structure as which a flat hierarchy of reflection can momentarily exist is not, I suggest, contradictory or even complicated, but neither is it quite obvious, or in any way identical to the statement of the problem; it seems just complex enough to be habitually missed by a philosophical reflection that does not keep in mind the form of diagonalization. Diagonalization involves just a few steps, but these must be the right steps in the right order. Any sufficiently elaborated reflection necessarily reproduces the problems to which diagonalization recognizably speaks, but setting the moments in the right order to produce the truth of incompleteness appears unlikely to happen by chance.

Diagonalization is a total structure of its moments, but having separated a manageable number of them for the sake of the understanding, we can now collect up, on the basis of both sides of the preceding discussion, a discrete plurality of points of correspondence that reciprocally map pure reflection to diagonalization:

1. Each is a local structure emerging as a consequence of a general reflexive structure, but not intuitively predictable on its basis.

2. Each bears on an ideal totality, and negates it punctually. Their exemplary object is a proposition expressing lack, or essential incompleteness.

3. Each establishes a bridge, outside the ordinary adequacy of representation, between an excess of intension and an excess of extension.

4. Each displaces one fixed point-the fixed point of negation projected as value or being in-and-foritself-and finds another, making the truth of incompleteness out of the impasse of inconsistency.

5. Each, by crossing two levels of iconic representation, succeeds also in causing an intersection between the iconic signifying relation of knowledge and the indexical signifying relation of existence.

6. Each reverses the normative arrow from the two to the one, which reversal rewrites the structure of value. The slogan here is: from two-in-order-to-be-one to one-in-order-to-be-two. This reversed value repeats, now at the level of a cognizable truth, the initial factical duality between its terms: the duality in-itself/for-itself (or consistency/completeness) rises from a perpetual but marginal disappointment to a reflective theme. The difference in-itself/for-itself is now for-itself. 
Recall, in this context, that the explicit project of the phenomenologist (i.e., the philosophical narrative voice) in Being and Nothingness is to establish the relation between the in-itself and the for-itself. At the same time, the for-itself's own project is to establish that relation not in the sense of discovering what it is but in that of bringing about what it wishes it to be. The outcome of that text at both levels and in their intersection is that the relation between in-itself and for-itself divides into a two that reduplicates its terms. This radically non-Cartesian dualism of Sartre's admits of metalogical analysis.

The two logical propositions essential to a correct reading of Being and Nothingness then amount to two repetitions, or two failed surpassings of duality:

1. The intentionality-excluding relation (viz. identity) of in-itself and for-itself is just the in-itself. $R_{e s}(e s, p s)=e s$. (This is awkwardly split in Being and Nothingness between the facticity of the for-itself and the "metaphysical" question of the emergence of the for-itself, which is ruled out of bounds.)

2. The intentionality-including relation of in-itself and for-itself is just the for-itself. $R_{p s}(e s, p s)=p s$. ([L] e pour-soi et l'en-soi sont réunis par une liaison synthétique qui n'est autre que le pour-soi lui-même. ${ }^{31}$ "[T]he for-itself and the In-itself are reunited by a synthetic connection which is nothing other than the For-itself itself." ${ }^{32}$ )

Observations:

1. It takes these two propositions to say positively what one says negatively in a single proposition: that the in-itself-for-itself is a contradiction. This impossibility claim is the organizing thesis of the a priori atheological dialectic of Being and Nothingness, but no one, including Sartre, has stated in a satisfactory way what precisely makes the in-itself-for-itself contradictory. In fact, I suggest, the in-itself-for-itself turns out to be one of the characteristic totalities, in which negation would have to have a fixed point, which stand as the hypothesis for reductio in diagonal arguments, while the very structure of the foritself as nihilation and having-to-be is equivalent to the rule that negation is fixed-point-free. The two logical rules given above are indispensable to the presentation of this isomorphism, and to that of the corresponding one between pure reflection and diagonalization. Please note, I do not at all imply that philosophical progress is only made in the positive assertions. Quite to the contrary, the philosophical position I call "negative foundations" in the next section is premised on the idea that, just as with Sartre's thesis, the most significant philosophical truths are negative truths. The pair of positive, dual, propositions helps us see how to put the synthetic negative insight to use, not to replace it with their conjunction.

2. What is broken apart here, on one level, as it were, also unifies. The for-itself coincides with itself qua for-itself (across reflective levels, bringing (only) a properly ethical stability to the successor of value) to the extent that it does not coincide with itself on the plane of the in-itself. (This is an explicit theme of the Cahiers, What is Literature?, and Beauvoir's Ethics of Ambiguity.)

3. Diagonalization both embodies and helps to clarify the global structure, or plot, of Being and Nothingness with striking concision. The for-itself's problem, at the level of lack, keeps dilemmatically ramifying. It wants to establish a mediating relation between itself and the in-itself, while this dyad is in one sense already mediated, and in the dual sense is without need of mediation. On the one hand, from the side of the for-itself, the relation is already mediated-the for-itself already is its own relation to the in-itself, the relation being-of, and this is all the relation it is ever going to get. On the other hand, from the side of the in-itself, the relation is without need of mediation-the for-itself lacks the in-itself, while the in-itself does not lack the for-itself. The for-itself projects a further mediation beyond this duality-it wants its identity to lie inside itself as for-itself and not (just) as in-itself, and for its transcendence not only to relate (as mere for-itself) but to be related (in-itself) to the in-itself. These failed internalizations and externalizations, respectively, are not two distinct doomed projects, but two ways of developing, in the consistent setting of theory, the for-itself's contradictory desire to be in-itself-for-itself. This search for an impossible mediation by an unhappy consciousness is the plot, so to speak, of Being and 
Nothingness, up to the point of a new reflective interaction of this reflection with the (at first external) reflection of the philosophical voice on this impossibility.

4. Diagonalization shows that these propositions, so recognizably Sartrean, do not depend on adopting a standard Sartrean model of in-itself and for-itself, but apply in any setting in which a minimal intentionality-a relation of being-of with sufficient expressive power to represent a small fragment of arithmetic, or, equivalently, to encode its own syntax-supervenes on relations of being. In the self-imposed phenomenological methodology of Being and Nothingness, on the other hand, the in-itself and for-itself, while not actually identified with matter and consciousness, have an irresistible tendency to drift in that direction, and these, as has been observed, may not be sufficiently developed categories to do the ontological work Sartre expects of them, especially at points where signification, the body, relations inside the in-itself, etc. come into play. And, of course, formal considerations are explicitly avoided in Being and Nothingnessyet with a systematicity and conceptual energy that causes them to be legibly inscribed on the underside, as it were, of each phenomenological assay. Recognizing this formal potentiality at a more abstract and more useful level than that of the matter/consciousness model we can say that the central proposition of both the theory of pure reflection and of diagonalization is that there necessarily is not an at-least-minimallyintentional being which is exactly what it is of, and is of exactly what it is.

5. Because of his adherence to his own standard phenomenological model, Sartre is unable consistently to articulate the central concept of his own system, pure/purifying reflection. Among the acknowledged consequences of this is a lack of determinacy concerning the fate of the ideal of the in-itself-for-itself in a purifying reflection: is this contradiction structurally inevitable, overcome, replaced, bracketed, etc.? Each of these interpretations is defended in the secondary literature, but, on my view, one cannot make progress on this point without observing the formal distinction between the locally affirmative and globally negative functions of the diagonal witness to contradiction. On a nonstandard model which brings together Socratic-Platonic cognitivism with Sartrean detotalization, purifying reflection is the process by which desire is transformed by metalogical duality to the extent that it learns how so to be transformed in the refutation of pre-reflective desire. Pure reflection yields the knowledge that the in-itself-for-itself is a contradiction, and the for-itself is converted by integrating the consequences of this knowledge at every functional level, not only in its discourse, but in its perception and emotion.

\section{Negative foundations}

We can now turn to some of the metaphysical and metaphilosophical consequences of the translation sketched above between pure reflection and diagonalization, a position which I shall call "Negative Foundations," and rejoin our observations on method in the first section with benefit of these results. The first point to be emphasized is that negative foundations are not inconsistent foundations, but rather foundations on the truth of incompleteness. Metalogical interpretation does not involve embracing dialetheism, so when I say that $X$ is a witness to the proposition " $P$ is contradictory", and deploy this syntax in discussing the relation of the event of pure reflection to the ontological thesis that the in-itself-for-itself is a contradiction, I mean first of all that it negates that ideal. It does not paradoxically both-negate-and-affirm it, or show it to be contradictory-but-assertable, or anything of that sort. At this point, rather, the spell is broken, even if we do not know how (yet) to put the breaking of the spell to use, or to say "positively" what is there negatively shown. Metalogical analysis yields a resolute solution to the post-conversion status of preconversion value: it is refuted. And yet the value shown to be contradictory seems to be an inevitable posit for both the for-itself and reason. But there is no conflict here. There is nothing contradictory about reason's having to posit a hypothesis which falls to apophasis/reductio. In fact, we can frame a simple argument (call it the Argument for Negative Foundations) that any single (true) genuinely ontological proposition has to be negative in precisely this way. It has to have the form, " $X$ necessarily does not exist" where $X$ is some name for the Absolute. Why? Because meaning is differential. Grant this and the inference is immediate. The only way to provide a characterization is by contrast, by drawing a distinction, and with what can Being be contrasted? Only with what necessarily does not exist. 
The ancients were therefore by no means mistaken to maintain that a characterization of being must proceed by way of reference to a perfect being; they simply mistook the sign of the proposition, taking for theology what is properly atheology. This is why it is valid for Sartre to maintain the structural, ontological importance of the nonexistence of God, despite the apparently reactive position that it seems, to the friends of some supposedly pure affirmation, to leave him in, and why the corresponding Cantorian form of the same thesis appears at the head of each of Badiou's major works. That there can be no avoidance of ontotheology, for non-historical reasons, makes it clear at what point the solution to the problems of reason's dissatisfaction and limits in negative foundations is non-Heideggerian. Neither is it Kantian, because the question of the synthesis of consistency and completeness is neither illicit nor paradoxical. Finally, of course, it is not Hegelian, since the Hegelian synthesis is precisely what is negated.

The dilemma of reflection, as we have seen, takes multiple forms even in Being and Nothingness, but one of them especially exercises Sartre's methodological attention. One need not put the dilemma of reflection in this way, but it is natural for Sartre, thinking on a vector that passes from Descartes to Bergson, to put it like this: Is the Cogito, which is supposed to deliver certain (and true) self-knowledge, instantaneous or not, given that the ipseity aimed at in reflection, my stream of consciousness, is temporally extended? We may note that this is a way of asking whether the Cogito is one or multiple, in the context of the general temporal and empirical biases of post-Kantian philosophy, extending into phenomenology. The question is dilemmatic because either outcome turns out badly, both from a methodological perspective, and what for Sartre amounts to the same (and has attracted more attention from readers of Being and Nothingness) from a concrete existential perspective. If the Cogito is instantaneous, there is a lack of shared being with the being known. And if, as the dialectician has reason to believe, the principle like-knows-like can only be deferred from activation for a finite number of steps of argumentation, then we suspect that whatever a timeless Cogito succeeds in knowing is itself some timeless proposition, ideal object, or generic image of consciousness, but not the real thing, this very consciousness. But if the Cogito is itself temporal, woven into the same temporal fabric as its referent, loss of certainty results. A knowledge that has to be synthesized across time looks to Sartre like empirical probability, not rational certainty, and what is for Sartre problematically the same thing, ${ }^{33}$ whatever unfolds itself in adumbrations (Abschattungen) belongs to the in-itself anyway. So if the Cogito is instantaneous, we have a lack on the side of being and truth, while if it is extended, we have a lack on the side of knowledge and certainty. To view the dialectic of in-itself and for-itself as driven and focused by an attempt to overcome the duality of truth and certainty certainly underlines the extent to which Hegel's logic is operating in Being and Nothingness even where it is explicitly refused; and is useful for seeing that the dilemma of reflection drives Hegel's dialectic: Hegel is also (already) a negative Cartesian in that, at least in the Phenomenology, the Cogito functions as the engine of the negative. The difference between Hegel's negative Cartesianism and Sartre's, of course, lies in the status of the projected synthesis, the unity of substance and subject or the drive toward the in-itself-foritself. Sartre infinitizes Hegel's reinterpretation of the Cogito as anti-substance by positing that the point of synthesis is not only non-actual but is irredeemably contradictory, even in the infinite case, and therefore must, in some way, be traversed in order to escape from the theological fantasy.

But we can gain a still-more-complete contextualization by noting that the dilemma provides a natural positioning of Sartre relative not only to Hegel but to Plato. To put it in something like the language of the Parmenides, suppose that the multiple (or a multiple) needs to have self-knowledge. Will the knower be the one or the multiple? If it's the one, it fails because it's not self-knowledge but other-knowledge, knowledge of what is unlike. To be self-knowledge, then, it has to be the multiple that knows the multiple; but the selfknowing then lacks the necessary unity of knowledge. It seems that self-knowledge fails either on the side of multiple-being or on the side of the one of knowledge.

Note that the problem of the relation of meaning and extension is one of the central problems for a theory of truth. To say that a proposition is true is to say that it is true somewhere. This is not my interpretation; it is the intrinsically topological character of model theory that speaks here. (The following, for instance, is a

33 Problematically because it equates ideal and real objects too quickly, and because it calls the question of Sartre's simultaneous appeal to and neglect of multiplicity in the in-itself. 
perfectly good question of mathematical ontology: Is it the case that whatever is true is true on some open interval? On some closed interval? etc.) Model theory is always finally topological. The question is always, starting from the trivial model of a set of propositions (i.e., first-order logic), what folds, tears, collapses, are possible that change not the propositional "meaning" but the global sense? The topological problem of the Cogito, likewise, lies in the impasse between the pointlikeness of certainty and the extension necessary to accomplish a reflection in and on the stream of consciousness. Whether you call it self-consciousness, selfknowledge, or self-reference, the same topological problem is posed: the formal punctuality of truth and the lived extendedness of reflexivity contradict each other, so that it seems that self-knowledge is impossible, and with it, an intelligible relation between form and existence.

Two general lines of inadequate solution are immediately recognizable. 1) One may assert that the duality can be overcome, as a concrete universal whose form is that of the in-itself-for-itself, or consistencycompleteness. 2) One may assert that the duality is internal to the for-itself. (Phenomenologically speaking, this is to contrast intentionality and its object within the intentional setting, and to ignore the question of the being of intentionality.) Both of these amount to forms of idealism. In the first case, consciousness asserts its identity with what opposes it, while in the second, it asserts that the latter does not exist. In addition, 3) I rule out solutions in which the bulk of the work is done by a change of terminology: self-knowledge and self-consciousness are, for instance, certainly different in the first person, but it simply does not follow that a solution to the problem is arrived at by drawing this distinction between a knowledge that I can represent reflectively, and a reflection which I am; the fundamental unclarity of self-reference before diagonalization persists.

The solution I propose will appear to orthodox phenomenologists like a formalist trick. It would have seemed that way to Sartre, which is why, I think, he resists putting it this clearly. In a way it is a formal trick, but disappointment at this should be bracketed if it can be shown that it is precisely the trick needed here: not merely an appeal to life to solve all formal problems, but a genuine relation of form and life, explicable from both sides. A certain kind of truth-recognition of a contradiction-seems uniquely to transcend the requirements of localization. This is, on reflection, both obvious and coherent with the general localization of truth: if what exists exists locally, the only trans-local truth is negative, pertaining to what intrinsically does not exist. The absolutely negative, in this sense, can uniquely be true not just at a point or on a region, but everywhere, without becoming thereby extended and positionally relative. To begin from a mathematical example: that "the greatest prime number" is a contradiction is true. True where? True throughout the model, true everywhere. Each term of the model is conditioned, and interestingly so, by not being it. That the nonexistence is interesting, even if, in this first example, modestly so, is crucial, for the suspicion naturally arises that with negative truths one is dealing with a banal series of the sort, "Whatever exists is not a triangular circle ... is not a square circle ... is not a pentagonal circle..."-incontestable truths on the cheap, and all completely irrelevant in this form. Can a ubiquitous contradiction also be significant? It can-here we are essentially instructed by the painstaking labor of Sartre's phenomenological description of value, alternatively the in-itself-for-itself, God, the perfect, or, on my metalogical interpretation, the synthesis of consistency and completeness. If it is this structure which is shown to be contradictory, then the truth of the proposition witnessing this contradiction both obtains everywhere and is also of the highest significance for existence.

\section{References}

Badiou, Alain. Being and Event. Translated by Oliver Feltham. London; New York: Continuum, 2005.

Badiou, Alain. L'Immanence des vérités: L'être et l'événement, 3. Fayard, 2018.

Badiou, Alain. Logics of Worlds: Being and Event, 2. Translated by Alberto Toscano. London; New York: Continuum, 2013.

Badiou, Alain. Theory of the Subject. Translated by Bruno Bosteels. London: Bloomsbury, 2013.

Beauvoir, Simone de. The Ethics of Ambiguity. Translated by Bernard Frechtman. New York: Philosophical Library, 1949.

Boolos, George, and Richard C. Jeffrey. Computability and Logic. Edited by John P. Burgess. 5th ed. Cambridge University Press, 2007.

Bova, J. A Metalogical Approach to the Problem of Reflexivity in Platonic Dialectic. Unpublished dissertation. 2016. 
Cannon, Betty. "Psychoanalysis and Existential Psychoanalysis," Ch. 7 in Sartre: Key Concepts. Edited by Stephen Churchill and Jack Reynolds. Routledge; New York: 2013.

Cantor, Georg. "On an Elementary Question in the Theory of Manifolds (1891)." In From Kant to Hilbert a Source Book in the Foundations of Mathematics. Volume 2, translated by William Bragg Ewald. Oxford; New York: Oxford University Press, 2005.

Chaitin, Gregory J. Thinking about Gödel and Turing: Essays on Complexity 1970-2007. Hackensack, N.J.: World Scientific, 2007.

Davis, Martin. The Undecidable; Basic Papers on Undecidable Propositions, Unsolvable Problems and Computable Functions. Hewlett, N.Y.: Raven Press, 1965.

DeLong, Howard. A Profile of Mathematical Logic. Reading, Mass.: Addison-Wesley Pub. Co., 1970.

Fitting, Melvin. Incompleteness in the Land of Sets. Studies in Logic vol. 5. College Publications, 2007.

Fraser, Olivia Lucca. “Nothingness \& Event” 2009 (Unpublished manuscript).

Fraser, Olivia Lucca. This Infinite, Unanimous Dissonance: A Study in Mathematical Existentialism Through the Works of Jean-Paul Sartre and Alain Badiou Unpublished manuscript)

Gödel, Kurt. On Formally Undecidable Propositions of Principia Mathematica and Related Systems. New York: Dover Publications, 1992.

Grim, Patrick. The Incomplete Universe: Totality, Knowledge, and Truth. Cambridge, Mass.: MIT Press, 1991.

Hofstadter, Douglas R. Gödel, Escher, Bach: An Eternal Golden Braid. New York: Basic Books, 1979.

Hofstadter, Douglas R. "What Is It like to Be a Strange Loop?" In Self-Representational Approaches to Consciousness, edited by Uriah Kriegel and Kenneth Williford. Cambridge, Mass.: MIT Press, 2006.

Hunter, Geoffrey. Metalogic: An Introduction to the Metatheory of Standard First Order Logic. Berkeley: University of California Press, 1971.

Kleene, Stephen Cole. Introduction to Metamathematics. New York: Van Nostrand, 1952.

Miguens, Sofia, Gerhard Preyer, \& Clara Bravo Morando eds. Pre-Reflective Consciousness: Sartre and Contemporary Philosophy of Mind. Routledge. 2016.

Petersen, Uwe. Diagonal Method and Dialectical Logic: Tools, Materials, and Groundworks for a Logical Foundation of Dialectic and Speculative Philosophy. Osnabrück: Der Andere Verlag, 2002.

Plato. Charmides, Translated by Rosamond Kent Sprague. In Complete Works, edited by John M Cooper and D. S Hutchinson. Indianapolis, Ind.: Hackett Pub., 1997.

Priest, Graham. Beyond the Limits of Thought. Cambridge; New York, NY, USA: Cambridge University Press, 1995.

Priest, Graham. The Nature of Philosophy and its Place in the University. University of Queensland Press, 1991.

Putnam, Hilary. Representation and Reality. Cambridge, Mass.: MIT Press, 1988.

Sartre, Jean-Paul. Being and Nothingness: An Essay on Phenomenological Ontology. Translated by Hazel Barnes. New York: Washington Square Press, 1992.

Sartre, Jean-Paul. “Intentionality: A fundamental idea of Husserl's phenomenology.” Translated by Joseph Fell. Journal of the British Society for Phenomenology 1 (2): 4-5, 1970

Sartre, Jean-Paul. L'être et le néant: essai d'ontologie phénoménologique. Gallimard, 2016.

Sartre, Jean-Paul.. Notebooks for an Ethics. Translated by David Pellauer. Chicago: University of Chicago Press, 1992.

Sartre, Jean-Paul. The Transcendence of the Ego: A Sketch for a Phenomenological Description. Translated by Andrew Brown. London; New York: Routledge, 2004.

Sartre, Jean-Paul. What Is Literature? New York: Harper \& Row, 1965.

Smullyan, Raymond M. Gödel's Incompleteness Theorems. New York: Oxford University Press, 1992.

Smullyan, Raymond M. Recursion Theory for Metamathematics. New York: Oxford University Press, 1993.

Yanofsky, Noson S. "A Universal Approach to Self-Referential Paradoxes, Incompleteness and Fixed Points." arXiv:math/0305282, May 19, 2003. 